12th LUMEN International Scientific Conference Rethinking Social Action. Core Values in Practice | RSACVP 2019 | 15-17 May 2019 | lasi - Romania

\title{
An Empirical Research for Identifying and Analyzing the Identity Characteristics of Different Online Destination Websites
}

Victor-Alexandru BRICIU, Arabela BRICIU, Ana-Maria GULPE https://doi.org/10.18662/lumproc. 150

How to cite: Briciu, V.A., Briciu, A., \& Gulpe, A.-M. (2019). An Empirical Research for Identifying and Analyzing the Identity Characteristics of Different Online Destination Websites. In C. Ignatescu (ed.), 12th LUMEN International Scientific Conference Rethinking Social Action. Core Values in Practice, 15-17 May 2019, Iasi - Romania (pp. 26-39). Iasi, Romania: LUMEN Proceedings. https://doi.org/10.18662/lumproc.150 


\title{
An Empirical Research for Identifying and Analyzing the Identity Characteristics of Different Online Destination Websites
}

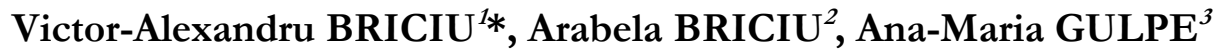

Abstract

The online environment and the other digital media have revolutionized human interaction. This is the network effect that organizations must use to reach their goals, and the destinations management organizations are also included in finding better solutions for promoting, communicating and marketing the desired place. This online presence of billions of people can be used both in organizational communication activities and in other areas, for research or facilitating professional activities. In this light, the research objective is to identify the Internet usage from the managerial point of view, i.e., the destination branding management of websites. The research study will try to specify and analyse the main features of destinations websites or the principal dimensions of their online identity, by applying a content analysis method scheme on 10 selected destination websites. Findings from the study suggest that the Web 1.0 paradigm is still being used or promoted, rather than the participatory $W$ eb 2.0, that nowadays is associated with a large range of tools and software used for viewing and developing the websites, allowing the users to interact directly with any web content in order to obtain custom rewards. Changes are taken into consideration by the destinations management organizations in terms of transmitting the information with greater visibility to targeted audiences. The online environment is, therefore, in favour of any organization that wants to be connected to this world of technology and professionalism.

Keywords: identity characteristics; destinations; brands; branding; websites.

\footnotetext{
${ }^{1}$ Lecturer, PhD, Transilvania University of Brasov, Brasov, Romania, victor.briciu@unitbv.ro.

${ }^{2}$ Lecturer, PhD, Transilvania University of Brasov, Brasov, Romania, victor.briciu@unitbv.ro.

${ }^{3}$ M.A., Transilvania University of Brasov, Brasov, Romania, anamaria2595@yahoo.com.

* Corresponding author.
} 
Victor-Alexandru BRICIU et al. | Lumen Proceedings 9 | RSACVP2019

\section{Introduction}

Nowadays, everything is constantly changing, evolving, developing rapidly and influencing the events that take place in everyday life. A particular transformation is related to the development of the Internet that became the most used tool for organizations and customers. In this light, it is stated that "the information online is now the main influence on the decisions of the consumer in the most important markets." [1].

Destinations have therefore the possibility to gain more and more in terms of information sharing from the Internet development with direct benefits for different locations. The role of these online portals, as means of information or communication for individuals searching for destinations to explore is beneficial "at the time of exploration and selection of the destination, in the planning stage of the journey, when booking services, during the visit and in the subsequent phase" [1].

Another important characteristic when discussing the features of websites in terms of destinations is defined by the visual attractiveness or "aesthetics" [10]. "Website aesthetics include: pictures, colours and graphical layouts" [8]. Therefore, all of these dimensions generate "visual appeal and information transfer" [11].

\section{Problem Statement}

This paper will focus on the problematic of the Internet usage from the managerial point of view, i.e., the destination branding management of websites or the "use the Internet's potential in order to communicate their online identity" [4]. The following research study will try to specify and analyse the main features of destinations websites or the principal dimensions of their online identity.

\section{Research Methods}

In this study a descriptive research was designed in terms of methodological terms and to achieve the goals stated before, the content analysis was used as the research method. From the beginning of analysis, it was found that "a unanimously agreed model was not developed in the branding sphere. Therefore, the analysis methods used in other fields were adopted" [4]. As presented by scholars, "content analysis is an observational research method which aims to systematically evaluate the symbolic content" [9] of different sort of written information. Gibson and Ward 
suggest that "although content analysis in general, and of media sources in particular, has a long and established pedigree, analysis of Web sites is a recent area of study" [7]. The study corpus refers to defining the objects to be studied. In our case, the corpus for analysis is well defined, meaning that the webpages of different destinations were selected. To be noted that these websites do not represent deliberate actions of destination branding by authorities in charge of managing the online platforms. However, "the websites will be considered communication sources" [6] that can generate branding effects.

An important part of the research is selecting the sampling unit and according to Earl Babbie, the non-probability sampling technique used in this study implies choosing the sampling units based on the researcher's opinion. These units are the one considered by the researcher the most useful and representative for the study [2]. To be notated that the territorialadministrative organizations chosen for the sampling unit does not represent a criterion of selection. However they represent intentional acts of online promotion of destination branding by the public authorities. In the final stage, 10 different official webpages of destinations were obtained, "firstly, taking into account national and international destinations; secondly, incorporating different kinds of destinations (cities, regions, countries and nations); and lastly, seeking variability in terms of geographical location, and the tourist-based potential, the maturity of the destination and the resources at hand to promote it" [5]. The list of these analysed websites is composed of: (1) France's website, in.france.fr; (2) Paris' website, en.parisinfo.com; (3) Normandy's website, en.normandie-tourisme.fr; (4) United States of America's website, www.visittheusa.com; www.visitcalifornia.com; California's website, www.discoverlosangeles.com; (7) New York City's website, www.nycgo.com; (8) Japan's website, www.jnto.go.jp; (9) Thailand's website, www.tourismthailand.org and (10) Bangkok's website, www.bangkok.com, using insights from World Tourism Organization official statistical data and reports [12], [13].

The multidisciplinary content operationalization was imperative to the study one-size-fits-all methodology for analyse the main features of destinations websites or the principal dimensions of their online identity does not exist. That is the main reason for defining a specific coding scheme or coding grid suggested by scholars: "the key utility of the scheme lies in the fact that it offers a standardized tool for entering information about Web sites" [7]. 
Victor-Alexandru BRICIU et al. | Lumen Proceedings 9 | RSACVP2019

\section{Findings}

After analysing the 10 websites of different destinations brands the results presented in the following paragraphs show the degree of Internet usage from the destination branding management point of view and the level of understanding of using the online advancement to promote and communicate the main features of destinations websites or the principal dimensions of their online identity. In the same time, the study will show whether these means of online communication are passive (informative) or active (interactive) channels for targeted groups or publics.

France's website, http://in.france.fr/, results:

The visual presentation dimension has 3 out of 6 elements present on the website: the destination brand logo, several maps and picture collections. For the brand behaviour dimension, the website scored 3 out of 5 points. The indicators for the brand behaviour dimension found on the website are: "the news section, the events calendar and the name of the authority under which the destination brand exists" [4], as defined in previous research literature. Brand information and communication dimension scored 11 out of 20 elements presented on the website. The results on the sub-dimensions found are the following: 4 out of 5 elements for the downward information flow sub-dimension are present on the website (the only one missing is the customize information for target audiences such as brochures); 2 out of 3 elements for the upward information flow sub-dimension are present on the website (the element missing is the offers one); 1 out of 2 elements for the lateral/horizontal information flow sub-dimension is present on the website (internal links are not used on this website); 3 out of 7 elements for the asynchronous interactive information flow sub-dimensions are present on the website (the site search, the ways of contact and the newsletter elements) and 1 out of 3 elements for the synchronous interactive information flow sub-dimensions is present on the website (the social media connection element).

The site delivery dimension has gained a 6 out of 15 score while other elements such as the dimension of the Homepage in $\mathrm{kb}$ and the number of links for other external sources were evaluated by the number of $\mathrm{kb}$ or links. The presence and appearance sub-dimension has 2 out of 6 elements present on the website: mobile icons/imagines/animated text and video materials. The accessibility sub-dimension has 1 out of 4 elements present (the translation of the page) and the size of the $\mathrm{kb}$ on the Homepage is $55 \mathrm{~kb}$ which according to the J. Nielson's rule [7] is not good because a page larger than $30 \mathrm{~kb}$ takes too much time to load. The navigability subdimension has 3 out of 4 elements present, the only one missing are the tips 
to make the navigation easier. The freshness sub-dimension is not present on the website and the visibility sub-dimension has received the forth position from all of the websites analysed.

The results show that this official website uses 23 defined elements $(50 \%)$ from the coding scheme of the destination online identity, suggesting in the same time to be a static environment defined in the Web 1.0 paradigm, a place where you can find information instead of a forum for sharing ideas about the destination, as in the more social and interactive Web 2.0 perspective.

Paris' website, https://en.parisinfo.com/, results:

The visual presentation dimension has 2 out of 6 elements present on the website: the picture gallery and the maps. The brand behaviour dimension has 3 out of 5 elements present on the website: a calendar for different activities and events, the brand management organization title or the name of it and the weather conditions plug-in. For the brand information and communication dimension 13 out of 20 elements were present on the website. The results on the sub-dimensions found are the following: 4 out of 5 elements for the downward information flow subdimension are present on the website (the only one missing is the customize information for target audiences such as brochures element); all elements for the upward information flow sub-dimension and for the lateral/horizontal information flow sub-dimension present on the website; 3 out of 7 elements for the asynchronous interactive information flow sub-dimensions are present on the website (the site search, sign up as a member and the newsletter elements) and 1 out of 3 elements for the synchronous interactive information flow sub-dimensions is present on the website (the social media connection element).

The site delivery dimension has gained a 6 out of 15 score while other elements such as the dimension of the Homepage in $\mathrm{kb}$ and the number of links for other external sources were evaluated by the number of $\mathrm{kb}$ or links. The presence and appearance sub-dimension has 2 out of 6 elements present on the website: mobile icons/imagines/animated text and video materials. The accessibility sub-dimension has 1 out of 4 elements present (the translation of the page) and the size of the kb on the Homepage is $171 \mathrm{~kb}$ which according to the J. Nielson's rule [7] is not good because a page larger than $30 \mathrm{~kb}$ takes too much time to load. The navigability subdimension has 3 out of 4 elements present, the only one missing are the tips to make the navigation easier. The freshness sub-dimension is not present on the website and the visibility sub-dimension has received the third position from all of the websites analysed. 
The results show that this official website uses 24 defined elements $(52 \%)$ from the coding scheme of the destination online identity, suggesting also the prevalence for the Web 1.0 model and a less development of Web 2.0 features.

Normandy's website, http://en.normandie-tourisme.fr/, results:

The visual presentation dimension has 5 out of 6 elements present on the website; the only one missing is the flag. The brand behaviour dimension has 3 out of 5 elements present on the website: the news section, events calendar and the weather conditions plug-in. For the brand information and communication dimension 12 out of 20 elements were present on the website. The results on the sub-dimensions found are the following: 3 out of 5 elements for the downward information flow subdimension are present on the website (the one missing are the newsletters and the contact information elements); all elements for the upward information flow sub-dimension and for the lateral/horizontal information flow sub-dimension present on the website; 3 out of 7 elements for the asynchronous interactive information flow sub-dimensions are present on the website: "the option to download photos/pdf, the site search and the newsletter elements" [4], as defined in the previous research literature and 1 out of 3 elements for the synchronous interactive information flow subdimensions is present on the website (the social media connection element).

The site delivery dimension has gained a 6 out of 15 score while other elements such as the dimension of the Homepage in $\mathrm{kb}$ and the number of links for other external sources were evaluated by the number of $\mathrm{kb}$ or links. The presence and appearance sub-dimension has 2 out of 6 elements present on the website: mobile icons/imagines/animated text and video materials. The accessibility sub-dimension has 1 out of 4 elements present (the translation of the page) and the size of the kb on the Homepage is $121 \mathrm{~kb}$ which according to the J. Nielson's rule [7] is not good because a page larger than $30 \mathrm{~kb}$ takes too much time to load. The navigability subdimension has 3 out of 4 elements present, the only one missing are the tips to make the navigation easier. The freshness sub-dimension is not present on the website and the visibility sub-dimension has received the ninth position from all of the websites analysed.

The results show that this official website uses 26 defined elements $(56,5 \%)$ from the coding scheme of the destination online identity, being also a more Web 1.0 oriented site in terms of participatory interactions. results:

United States of America's website, https://www.visittheusa.com/,

The visual presentation dimension has 3 out of 6 elements present on the website: "the logo, the picture gallery and the maps" [3], as defined in 
the past research literature. The brand behaviour dimension has 1 out of 5 elements present on the website; the only one being management affiliation brand's name. About brand information and communication dimension were identified 8 out of 20 elements were present on the website. The results on the sub-dimensions found are the following: 2 out of 5 elements for the downward information flow sub-dimension are present on the website (the general information and travel tips elements); for the upward information flow sub-dimension the only element missing is the offers one, for the lateral/horizontal information flow sub-dimension all elements are present on the website; 1 out of 7 elements for the asynchronous interactive information flow sub-dimensions is present on the website (the site search) and 1 out of 3 elements for the synchronous interactive information flow sub-dimensions is present on the website (the social media connection element).

The site delivery dimension has gained a 5 out of 15 score while other elements such as the dimension of the Homepage in $\mathrm{kb}$ and the number of links for other external sources were evaluated by the number of $\mathrm{kb}$ or links. The presence and appearance sub-dimension has 2 out of 6 elements present on the website: mobile icons/imagines/animated text and video materials. The accessibility sub-dimension has 1 out of 4 elements present (the translation of the page) and the size of the kb on the Homepage is $656 \mathrm{~kb}$ which according to the J. Nielson's rule [7] is not good because a page larger than $30 \mathrm{~kb}$ takes too much time to load. The navigability subdimension has 2 out of 4 elements present (a Homepage icon on every subpage of the website and a main menu). The freshness sub-dimension is not present on the website and the visibility sub-dimension has received the last position from all of the websites analysed.

The results show that this official website uses only 17 defined elements $(37 \%)$ from the coding scheme of the destination online identity and is not well defined as a new Web 2.0 medium of brand interaction with the publics.

California's website, http://www.visitcalifornia.com/, results:

The visual presentation dimension has 3 out of 6 elements present on the website: the slogan, the logo and the maps. The brand behaviour dimension has 1 out of 5 elements present on the website; the only one being the management organization name of the destination. Regarding the brand information and communication dimension 13 out of 20 elements were present on the analysed website. The results on the sub-dimensions found are the following: 4 out of 5 elements for the downward information flow sub-dimension are present on the website (the one missing is the newsletters); for the upward information flow sub-dimension the only 
element missing is the offers one; for the lateral/horizontal information flow sub-dimension all elements are present on the website; 4 out of 7 elements for the asynchronous interactive information flow sub-dimensions are present on the website (the missing one are the online form for feedback, sign up as a member and voting polls) and 1 out of 3 elements for the synchronous interactive information flow sub-dimensions is present on the website (the social media connection element).

The site delivery dimension has gained a 6 out of 15 score while other elements such as the dimension of the Homepage in $\mathrm{kb}$ and the number of links for other external sources were evaluated by the number of $\mathrm{kb}$ or links. The presence and appearance sub-dimension has 2 out of 6 elements present on the website: mobile icons/imagines/animated text and video materials. The accessibility sub-dimension has 1 out of 4 elements present (the translation of the page) and the size of the $\mathrm{kb}$ on the Homepage is $176 \mathrm{~kb}$ which according to the J. Nielson's rule [7] is not good because a page larger than $30 \mathrm{~kb}$ takes too much time to load. The navigability subdimension has 3 out of 4 elements present, the only one missing are the tips to make the navigation easier. The freshness sub-dimension is not present on the website and the visibility sub-dimension has received the sixth position from all of the websites analysed.

The results show that this official website uses 23 defined elements $(50 \%)$ from the coding scheme of the destination online identity, completing the list of above analysed sites defined by the Web 1.0 static or passive environment.

Los Angeles' website, https://www.discoverlosangeles.com/, results:

The visual presentation dimension has 3 out of 6 elements present on the website: "the logo, the picture gallery and the maps" [4], as discussed in previous research. The brand behaviour dimension has 3 out of 5 elements present on the website: a calendar for different activities and events, the brand management organization title or the name of it and the weather conditions plug-in. For the brand information and communication dimension 10 out of 20 elements were present on the website. The results on the sub-dimensions found are the following: 2 out of 5 elements for the downward information flow sub-dimension are present on the website (the general information and the travel tips); for the upward information flow sub-dimension the only element missing is the offers one; 1 out of 2 elements for the lateral/horizontal information flow sub-dimension is present on the website (internal links are not used on this website); 3 out of 7 elements for the asynchronous interactive information flow subdimensions are present on the website (the site search, the newsletter and sign up as a member) and 1 out of 3 elements for the synchronous 
interactive information flow sub-dimensions is present on the website (the social media connection element).

The site delivery dimension has gained a 5 out of 15 score while other elements such as the dimension of the Homepage in $\mathrm{kb}$ and the number of links for other external sources were evaluated by the number of $\mathrm{kb}$ or links. The presence and appearance sub-dimension has 2 out of 6 elements present on the website: mobile icons/imagines/animated text and video materials. The accessibility sub-dimension has 1 out of 4 elements present (the translation of the page) and the size of the $\mathrm{kb}$ on the Homepage is $145 \mathrm{~kb}$ which according to the J. Nielson's rule [7] is not good because a page larger than $30 \mathrm{~kb}$ takes too much time to load. The navigability subdimension has 2 out of 4 elements present: a Homepage icon on every subpage of the website and a main menu. The freshness sub-dimension is not present on the website and the visibility sub-dimension has received the eighth position from all of the websites analysed.

The results show that this official website uses 20 defined elements $(43 \%)$ from the coding scheme of the destination online identity and is, as the other before mentioned sites, a more passive mean of communication and not designed for brand interaction with the targeted audiences.

New York City's website, https://www.nycgo.com/, results:

The visual presentation dimension has 3 out of 6 elements present on the website: "the logo, the picture gallery and the maps" [3], as defined in the past research literature. The brand behaviour dimension has 3 out of 5 elements present on the website: a calendar for different activities and events, the brand management organization title or the name of it and the board members of that authority of brand management. For the brand information and communication dimension 12 out of 20 elements were present on the website. The results on the sub-dimensions found are the following: 3 out of 5 elements for the downward information flow subdimension are present on the website: "the general information, customize information for target audiences such as brochures and the travel tips" [4]; all elements for the upward information flow sub-dimension and for the lateral/horizontal information flow sub-dimension present on the website; 3 out of 7 elements for the asynchronous interactive information flow subdimensions are present on the website: "the option to download photos/pdf, the site search and the newsletter" [4], as they were identified in other study and 1 out of 3 elements for the synchronous interactive information flow sub-dimensions is present on the website (the social media connection element).

The site delivery dimension has gained a 4 out of 15 score while other elements such as the dimension of the Homepage in $\mathrm{kb}$ and the 
number of links for other external sources were evaluated by the number of $\mathrm{kb}$ or links. The presence and appearance sub-dimension has 3 out of 6 elements present on the website: mobile icons/imagines/animated text, audio materials and video materials. The accessibility sub-dimension has no element present on the website and the size of the $\mathrm{kb}$ on the Homepage is $219 \mathrm{~kb}$ which according to the J. Nielson's rule [7] is not good because a page larger than $30 \mathrm{~kb}$ takes too much time to load. The navigability subdimension has 1 out of 4 elements present: the site index. The freshness sub-dimension is not present on the website and the visibility sub-dimension has received the fifth position from all of the websites analysed.

The results show that this official website uses 22 defined elements $(48 \%)$ from the coding scheme of the destination online identity and it is defined also as a more non-interactive brand platform, in comparison with the Web 2.0 online solutions.

Japan's website, https://www.jnto.go.jp/, results

The visual presentation dimension has 3 out of 6 elements present on the website: "the logo, the picture gallery and the maps" [4], as discussed in previous research. The brand behaviour dimension has 2 out of 5 elements present on the website: the news section and the brand management organization title or the name of it. Discussing the brand information and communication dimension, 12 out of 20 elements were present on the website. The results on the sub-dimensions found are the following: 4 out of 5 elements for the downward information flow subdimension are present on the website (the only one missing is the contact information); for the upward information flow sub-dimension 1 out of 3 elements is to be found (the cookies); for the lateral/horizontal information flow sub-dimension all elements are present on the website; 3 out of 7 elements for the asynchronous interactive information flow sub-dimensions are present on the website (the option to download photos/pdf, the site search and the online form for feedback) and 2 out of 3 elements for the synchronous interactive information flow sub-dimensions are present on the website (the social media connection element and smart applications).

The site delivery dimension has gained a 5 out of 15 score while other elements such as the dimension of the Homepage in $\mathrm{kb}$ and the number of links for other external sources were evaluated by the number of $\mathrm{kb}$ or links. The presence and appearance sub-dimension has 2 out of 6 elements present on the website: the intro component and the mobile icons/imagines/animated text. The accessibility sub-dimension has one element present on the website (the translation of the page) and the size of the $\mathrm{kb}$ on the Homepage is $851 \mathrm{~kb}$ which according to the J. Nielson's rule [7] is not good because a page larger than $30 \mathrm{~kb}$ takes too much time to load. 
The navigability sub-dimension has 2 out of 4 elements present: a Homepage icon on every subpage of the website and a main menu, as presented in the other analysed websites. The freshness sub-dimension is not present on the website and the visibility sub-dimension has received the first position from all of the websites analysed.

The results show that this official website uses also 22 defined elements $(48 \%)$ from the coding scheme of the destination online identity and shows a predominant character for the passive online environment of online destination.

Thailand's website, https:/ /www.tourismthailand.org/, results:

The visual presentation dimension has 4 out of 6 elements present on the website: "the slogan, the logo, the picture gallery and the maps" [4], as items defined in research literature. The brand behaviour dimension has 3 out of 5 elements present on the website: the news section, a calendar for different activities and events, the brand management organization title or the name of it. Brand information and communication dimension scored 14 out of 20 items present on the website. The results on the sub-dimensions found are the following: all elements for the downward information flow sub-dimension are present on the website; 2 out of 3 elements for the upward information flow sub-dimension are to be found (the only one missing is the offers); all elements for the lateral/horizontal information flow sub-dimension are present on the website; 3 out of 7 elements for the asynchronous interactive information flow sub-dimensions are present on the website: "the option to download photos/pdf, the site search and the ways of contact" [4] and 2 out of 3 elements for the synchronous interactive information flow sub-dimensions are present on the website (the live chat and the social media connection element).

The site delivery dimension has gained a 6 out of 15 score while other elements such as the dimension of the Homepage in $\mathrm{kb}$ and the number of links for other external sources were evaluated by the number of $\mathrm{kb}$ or links. The presence and appearance sub-dimension has 2 out of 6 elements present on the website: the intro component and the mobile icons/imagines/animated text. The accessibility sub-dimension has one element present on the website (the translation of the page) and the size of the $\mathrm{kb}$ on the Homepage is $86 \mathrm{~kb}$ which according to the J. Nielson's rule [7] is not good because a page larger than $30 \mathrm{~kb}$ takes too much time to load. The navigability sub-dimension has 3 out of 4 elements present, the only one missing being the tips to make navigation easier. The freshness subdimension is not present on the website and the visibility sub-dimension has received the second position from all of the websites analysed. 
The results show that this official site presents 27 defined elements $(59 \%)$ from the coding scheme of the destination online identity and is also defined by the limited interaction between website and users.

Bangkok's website, http://www.bangkok.com/, results:

The visual presentation dimension has 2 out of 6 elements present on the website: the picture gallery and the maps. The brand behaviour dimension has 3 out of 5 elements present on the website: a calendar for different activities and events, the brand management organization title or the name of it and the weather plug-in. For the brand information and communication dimension 9 out of 20 elements were present on the website. The results on the sub-dimensions found are the following: 2 out of 5 elements for the downward information flow sub-dimension are present on the website (the general information and the travel tips); all elements for the upward information flow sub-dimension and for the lateral/horizontal information flow sub-dimension are present on the website; 1 out of 7 elements for the asynchronous interactive information flow sub-dimensions are present on the website (the site search) and 1 out of 3 elements for the synchronous interactive information flow sub-dimensions are present on the website (the social media connection element).

The site delivery dimension has gained a 4 out of 15 score while other elements such as the dimension of the Homepage in $\mathrm{kb}$ and the number of links for other external sources were evaluated by the number of $\mathrm{kb}$ or links. The presence and appearance sub-dimension has 1 out of 6 elements present on the website: the mobile icons/imagines/animated text one. The accessibility sub-dimension has 1 element present on the website (the translation of the page) and the size of the $\mathrm{kb}$ on the Homepage is $266 \mathrm{~kb}$ which according to the J. Nielson's rule [7] is not good because a page larger than $30 \mathrm{~kb}$ takes too much time to load. The navigability subdimension has 2 out of 4 elements present: Homepage icon on every subpage of the website and an overall main menu. The freshness subdimension is not present on the website and the visibility sub-dimension has received the seventh position from all of the websites analysed.

The results show a lower score of 18 defined elements (39\%) from the coding scheme of the destination online identity and the destination website is generally designed in the Web 1.0 fashion, where one can only view the information that is displayed on the website by its administrator. 
Victor-Alexandru BRICIU et al. | Lumen Proceedings 9 | RSACVP2019

\section{Conclusions}

Destination branding management of websites is responsible for transmitting the relevant information to targeted audiences by using modern online solutions and platforms, providing useful details on the analysed dimensions: "brand design, brand behaviour, brand information and communication, and site delivery" [3], previously defined in research literature.

The research findings listed above must be taken into account under several limitations, one of these being the method used, as the online content alteration may be problematic to replicate the proposed study and also, by applying content analysis to the online environment, challenges may arise with possible content updates during or after the completion of the research so these effects should be considered in the analysis and interpretation of the results and in determining their degree of generalization or as a new direction of longitudinal research by replicating this research at another time.

\section{References}

[1] Alonso I, Bea E. A Tentative Model to Measure City Brands on the Internet. Place Branding and Public Diplomacy. 2012; 8(4): 311-328.

[2] Babbie Earl. The Basis of Social Research. Belmont, Publisher: Wadsworth Cengage Learning; 2010.

[3] Briciu V-A, Demeter R, Nechita F, Kavoura A, Briciu A. A Proposed Online Platform for Ranking Place Brands Identity Characteristics of Official Tourism Websites. In: Kavoura, Androniki, Kefallonitis, Efstathios, Giovanis, Apostolos, editors. Strategic Innovative Marketing and Tourism. Cham: Springer; 2019. p. 755-762.

[4] Briciu V-A, Nechita F, Demeter R, Kavoura A. Minding the Gap Between Perceived and Projected Destination Image by Using Information and Communication Platforms and Software. International Journal of Computational Methods in Heritage Science. 2019; 3 (2): 1-17.

[5] Fernández-Cavia J, Rovira C, Díaz-Luque P, Cavaller V. Web Quality Index (WQI) for official tourist destination websites. Proposal for an assessment system. Tourism Management Perspectives. 2014; 9: 5-13.

[6] Florek M, Insch A, Gnoth J. City Council Websites as a Means of Place Brand Identity Communication. Place Branding. 2006; 2(4): 276-296.

[7] Gibson R, Ward S. A Proposed Methodology for Studying the Function and Efectiveness of Party and Candidate Web Sites. Social Science Computer Review. 2000; 18(3): 301-319.

[8] Gulpe A-M, Briciu V-A, Demeter R. Opportunities and Limitations of Place Branding in the Online Environment. Chapter 2: Brands on the Internet. 
Available from:

https://www.researchgate.net/profile/Victor Alexandru Briciu/publication/ 324706154 Chapter 2 Brands on the Internet/links/5ade320ca6fdcc29358 d814f/Chapter-2-Brands-on-the-Internet.pdf?origin=publication detail.

[9] Kolbe RH, Burnett MS. Content-Analysis Research: An Examination of Applications with Directives for Improving Research Reliability and Objectivity. Journal of Consumer Research. 1991; 18(2): 243-250.

[10] Lavie T, Tractinsky N. Assessing dimensions of perceived visual aaesthetics of web sites. International Journal of Human-Computer Studies. 2004;60(3): 269-298.

[11] Luna-Nevarez C, Hyman M. Common Practices in Destination Website Design. Journal of Destination Marketing \& Management. 2012; 1 (1-2): 94106.

[12] UNWTO. Statement by the Secretary-General. Available from: http://cf.cdn.unwto.org/sites/all/files/pdf/a22 04 statement by the secret ary general en.pdf.

[13] UNWTO. UNWTO Tourism Highlights 2017 Edition. Available from: https://www.e-unwto.org/doi/pdf/10.18111/9789284419029. 